Aus der k. laryngologischen Poliklinik der Universität München. (Vorstand: Prof. Dr. Neumayer.)

\title{
Über Verkümmerung der Augenbrauen und der Nägel bei Thyreoidosen.
}

Von

Dr. R. Hoffmann,

I. Assiatent.

(Mit einer Abbildung im Texte.)

Bei einer Patientin, die wegen einer Nebenhöhleneiterung in Behandlung kam, konnte ich einen interessanten Nebenbefund erheben:

Es handelt sich um eine 27jährige, große, kräftige Bauersfrau aus Oberbayern. Die Augbrauen wie die Wimpern bestehen aus dunklen, kleinen, sehr kräftigen, stumpf endigenden Haarstummeln, so daß ich zuerst glaubte, sie seien versehentlich versengt worden. Die Länge der Augbrauenlinie beträgt etwa $5 \frac{1}{2}$ Zentimeter. Die Ansatzlinie des mäßig reichlichen, braunen Haupthaares ist zurückgesetzt, so daß eine hohe Stirn sichtbar ist.

Auch andere epitheliale Gebilde, die Nägel an Händen und FüBen sind kümmerlich entwickelt: Sie sind klein, der weiße Hof an der Basis fehlt; oben läuft der Nagel spitz aus, die Fingerkuppe ist in einer Höhe von mehr als $5 \mathrm{~mm}$ sichtbar. Im oberen Viertel verliert der Nagel seinen Glanz und die rosa durchschimmernde Farbe, er wird weil, brüchig, undurchsichtig. Der Nagel haftet mit seiner ganzen Fläche fest an der Unterlage. Seine Wölbung ist eine annähernd normale. Eine merkwürdige Konfiguration erhält der Nagel durch drei Impressionen, welche etwa 8/4 seiner Fläche einnehmen. Die mittlere, welche dem Abdruck einer 
Fingerkuppe in verkleinertem Maßstabe entspricht, ist größer, als die beiden seitlichen.

Der Nagel ist wohl dem Wachstum des Individuums entsprechend größer geworden, ein Beschneiden desselben war aber nie notwendig noch möglich.

Die Anamnese ergab folgenden Stammbaum:

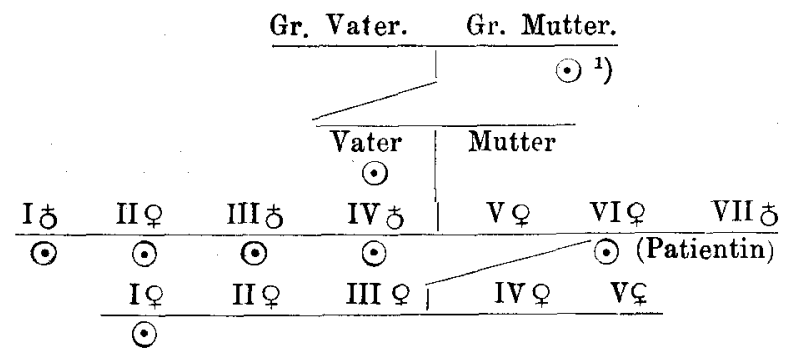

Es läßt sich also kein Vorwiegen des einen oder des anderen Geschlechtes feststellen. Die normalen Familienmitglieder sind die später geborenen, hei Geburt des ersten Kindes war die Patientin 18 Jahre alt, ein Alter, welches ja häufig von Störungen in der internen Sekretion bestimmter Drüsen z. B. Thyreoidea und Ovar begleitet ist.

Von ihren 6 Geschwistern (4 Brüder und 2 Schwestern) waren 3 Brüder und 1 Schwester anormal, von ihren 5 Kindern - lauter Mädchen, nur das älteste. Der Ehemann ist normal. Die Familieneigentümlichkeiten erbte der Vater der Patientin ron seiner Mutter.

Die Mißbildungen kommen auch bei der ferner stehenden Verwandtschaft der Patientin vor und werden von ihr als sichere Merkmale der Zugehörigkeit zu ihrer Familie angesehen.

Bemerkenswert erscheint, daß die Patientin eine mäßig große Struma (39 $\mathrm{cm}$ Halsumfang) aufweist, daß ferner ihre sämtlichen Geschwister, sowie ihre Mutter (auf den früh verstorbenen Vater kann sie sich nicht erinnern) vergrößerte Schilddrüsen haben. Allerdings ist zu berücksichtigen, daß die Patientin aus einer Kropfgegend stammt. Daß die Augbrauen

1) $\odot$ anormale Familienglieder. 
verkümmert und die Haargrenzen zurückgerïckt sind, findet man auch beim infantilen Myxödem. Vielleicht darf man einen Dysthyreoidismus als prädisponierend für die geschilderte Mißbildung von Augbrauen und Nägel ansehen. Bei unserer Patientin weist ein beschleunigter Puls (ca.90) und ein ganz leichter Exophthalmus auf einen Hyperthyreodismus hin.

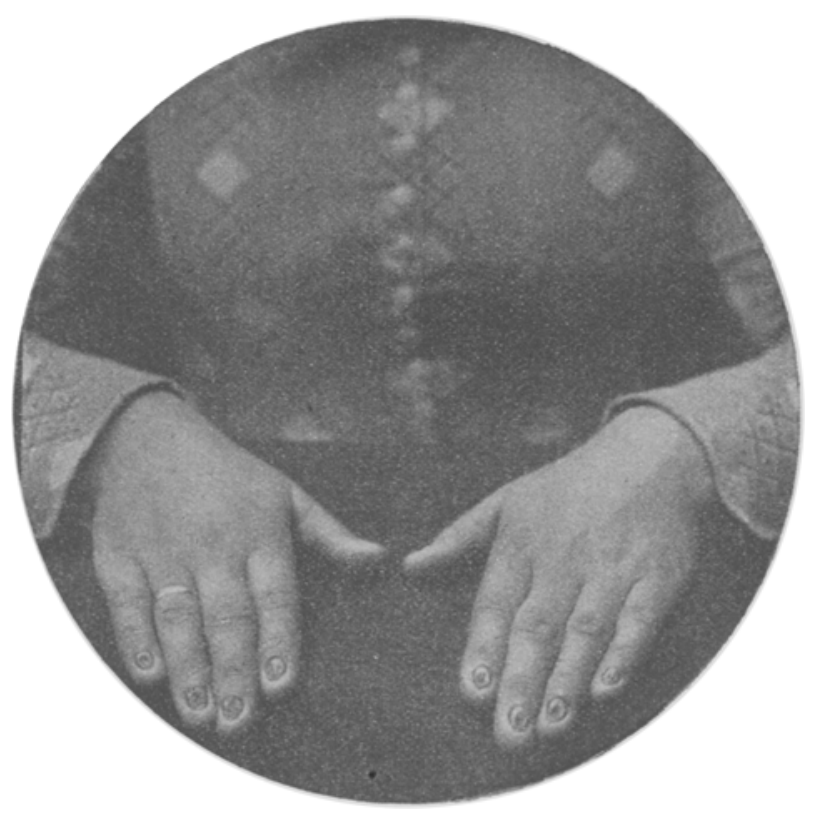

Gleichzeitig sah ich einen Fall von Hypothyreoidismus, welcher, wie die vorige Patientin, dieselbe Verkümmerung der Augbrauen neben einer Struma zeigte:

Der Patient ist 23 Jahre alt, Maler; der Halsumfang beträgt $42 \mathrm{~cm}$. Trotz der Vergrößerung der Schilddrüse zeigt er deutliche Zeichen des Hypothyreoidismus. Fr ist völlig bartlos (Schamhaare gut entwickelt), die Augbrauen bestehen aus kleinen Stummeln, die Grenzen des Haupthaares sind vorn und hinten herauf gerückt und zeigen "Geheimratswinkel“. Die Haare stehen sehr weit auseinander. Die Haut des Gesichtes und die Halses ist trocken, glanzlos, leicht abhebbar. Am Halse zeigt sie tiefe Falten, zwei in der Höhe des oberen Randes des Thyreoidknorpels laufen dicht nebeneinander parallel, so daß man zuerst glaubt 
eine Schnürfurche vor sich zu sehen. Der Gaumen ist abnorm hoch, dem Torus palati entsprechend erhebt sich eine etwa $1 \mathrm{~cm}$ lange, $4 \mathrm{~mm}$ hohe Leiste, die mit stark gewulsteter Schleimhaut besetzt ist. Die oberen Eckzähne fehlen, ohne daß eine Lücke sichtbar ist; sie saßen früher über den oberen äußeren Schneidezähnen und wurden vom Zahnarzt entfernt. Das äußere Ohr ist normal. Der Patient erhält Thyreoidin. 